\title{
O ciclo de políticas e o currículo vivido na educação física em uma escola de referência ${ }^{1}$
}

\author{
The policy cycle and the curriculum living in physical \\ education in a reference school
}

\section{El ciclo de políticas y el curriculo experimentado en la educación física en una escuela de referencia}

\author{
(iD) Alvaro Rego Millen Neto \\ Universidade Federal do Vale do São Francisco, Petrolina, Pernambuco, Brasil \\ e-mail: alvaro.millen@gmail.com \\ (iD) Cleuber de Souza Gonçalves \\ Universidade Federal do Vale do São Francisco, Petrolina, Pernambuco, Brasil \\ e-mail: cleubersgoncalves@gmail.com \\ iD João Paulo Silva de Oliveira \\ Instituto Federal de Educação, Ciência e Tecnologia da Bahia, Juazeiro, Bahia, Brasil \\ e-mail: joaopaulo.tdf@gmail.com
}

\begin{abstract}
Resumo: O estudo busca descrever e compreender como as políticas curriculares para a Educação Física (EF) da Secretaria de Educação de Pernambuco são acessadas e traduzidas em ações pedagógicas. A análise foi realizada através de uma pesquisa com características etnográficas em uma escola de referência. Para a coleta, foram utilizados um diário de campo, fichas de observação e entrevistas. Os dados foram organizados com análise de conteúdo. Os resultados mostram que as ações curriculares da escola de referência que abrigou a pesquisa são influenciadas pela ideologia da performatividade. Nas aulas de EF, essas ações concorrem com o usufruto da autonomia pedagógica do profes-
\end{abstract}

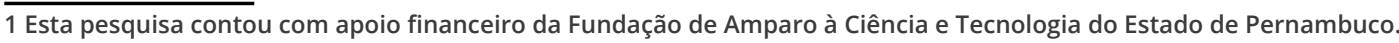


sor, que abdica das políticas efetivas presentes nos textos curriculares da Secretaria de Educação.

Palavras-chave: Educação Física. Currículo. Ciclo de Políticas. Escolas de Referência.

\begin{abstract}
The study seeks to describe and understand how the curriculum policies for Physical Education (PE) of the Pernambuco Department of Education are accessed and translated into pedagogical actions. The analysis was carried out through a research with ethnographic characteristics in a reference school. For collection, a field notes, observation forms and interviews were used. The data were organized with content analysis. The results show that the curricular actions of the reference school that housed the research are influenced by the ideology of performativity. In PE classes, these actions compete with the enjoyment of the pedagogical autonomy of the teacher, who renounces the effective policies present in the curriculum texts of the Department of Education.
\end{abstract}

Keywords: Physical Education. Curriculum. Policy Cycle. Reference School.

Resumen: El estudio busca describir y comprender cómo se accede y se traduce en acciones pedagógicas a las políticas curriculares de Educación Física (EF) del Departamento de Educación de Pernambuco. El análisis se realizó con una investigación con características etnográficas en una escuela de referencia. Para la recolección, se utilizó un diario de campo, hojas de observación y entrevistas. Los datos se organizaron con análisis de contenido. Los resultados muestran que las acciones curriculares de la escuela que acogió la investigación están influenciadas por la ideología de la performatividad. En las clases de EF, estas acciones compiten con la autonomía pedagógica del docente, que renuncia a las políticas efectivas presentes en los textos curriculares del Departamento de Educación.

Palabras clave: Educación Física. Currículo. Ciclo de Políticas. Escuela de Referencia.

Submetido em: 11-07-2020

Aceito em: 08-02-2021 
O ciclo de políticas e o currículo vivido na educação física em uma escola de referência Alvaro Rego Millen Neto • Cleuber de Souza Gonçalves • João Paulo Silva de Oliveira

\section{Introdução}

Stephen Ball concebeu um modo peculiar de compreender a relação entre as diferentes esferas do que tratamos como currículo. Esse sociólogo inglês desenvolveu, com a contribuição de Richard Bowe, a abordagem do "ciclo de políticas" (BALL; BOWE, 1992; MAINARDES, 2006). Tal perspectiva enfatiza a necessidade de se repensar a articulação entre os processos macro e micro nas análises das políticas educacionais. Ball (1994) se contrapõe às teorias que imputam rigidez às políticas curriculares e que, equivocadamente, têm uma percepção de política como algo estanque, coeso e unilateral. Em seu lugar, ele propõe modos de análise que levem em consideração a complexidade das dinâmicas inerentes ao campo das políticas. As políticas de currículo, como outras políticas, são lugares de representatividades e de embates para fazer valer diferentes ideologias e interesses. A circulação dessas ideologias e interesses nas diferentes esferas do currículo não tem um percurso exclusivo e predeterminado (do tipo de cima para baixo ou de baixo para cima), há uma grande teia de interesses constituída em um mapa global cujo fluxo segue, dialeticamente, por variadas direções (BALL, 2001).

A partir de suas críticas à noção de política como uma manifestação estanque e polarizada, Ball e Bowe (1992) formularam uma compreensão do que seria um ciclo de políticas contínuo, dinâmico e circular. Tal ciclo seria composto pelas seguintes esferas: as políticas pretendidas (intended policy), que constituem o contexto de influência; as políticas efetivas (actual policy), materializadas a partir da produção dos textos curriculares; e as políticas em uso (policy-in-use), expressadas nas práticas curriculares vividas no cotidiano. É importante destacar que essas diferentes esferas se inter-relacionam, não há uma dimensão temporal e tampouco são etapas lineares. Trata-se de uma complexa trama na qual as disputas e embates políticos se contrapõem e se relacionam constantemente. A seguir, apresentaremos, de forma sintetizada, as principais características dessas três esferas da dinâmica curricular. 
No contexto de influência se definem os discursos políticos e há uma arena de debate para se definir quais influências serão mais determinantes nas definições curriculares. Diferentes ideologias e interesses disputam espaço e influenciam o modo com o qual os responsáveis pelas formulações curriculares pensam e contribuem para delinear os projetos educacionais. Essas influências vão desde questões mais específicas até as de influência global na educação local. Para exemplificar as questões específicas, poderíamos pensar numa problemática própria de um componente curricular, tal como o projeto de formação esportiva via Educação Física (EF) que preconiza o desenvolvimento do esporte de alto rendimento. Essa problemática já foi discutida no campo acadêmico da EF brasileira e repercute na composição das influências dos formuladores de políticas curriculares, seja criticamente ou não. Sobre as questões mais globais, Ball (2001) tem apontado para as influências internacionais no desenvolvimento de políticas nacionais. Essas influências podem ser de duas naturezas, o que ele chama de transferência ou empréstimo de políticas e a imposição de determinadas "soluções" recomendadas por agências multilaterais. Um exemplo das transferências pode ser encontrado na forma pela qual foram elaborados os Parâmetros Curriculares Nacionais, que tiveram como consultor o psicólogo espanhol César Coll, também responsável pela reforma curricular espanhola (MOREIRA; MACEDO, 2006). Sobre as "soluções" transplantadas, já são bem conhecidas as influências de agências como o Banco Mundial, a UNESCO e o Fundo Monetário Internacional.

No contexto de produção de textos são estipuladas, a partir das influências que se estabeleceram politicamente, diretrizes para as ações práticas. Não se trata de uma transferência simples e evidente das influências para os documentos escritos. O contexto de influência está mais próximo dos interesses diretos, sejam específicos ou globais, e das ideologias dogmáticas. Os textos impressos, por sua vez, têm uma conotação mais pragmática, pois são diretrizes que representam (ou deveriam representar) os interesses da população e estão expostos à opinião pública. Essas diretrizes 
podem estar impressas em diferentes formatos, tais como documentos legais e oficiais, pronunciamentos oficiais, materiais didáticos, entre outros. A produção de textos também é um espaço de disputas e acordos, pois estão em jogo os diferentes interesses que buscam, através dos documentos legais, controlar o que é considerado válido enquanto conhecimento escolar (BALL, 1994).

Os textos curriculares têm consequências reais que são vivenciadas na terceira esfera da dinâmica curricular, o contexto das práticas curriculares vividas no cotidiano. É nesse contexto que as políticas expressas nos documentos legais são interpretadas. Para Ball, Maguire e Braun (2012), não há implementação de políticas curriculares, mas interpretações e traduções que geram transformações significativas nas políticas originais. As políticas não são simplesmente transferidas para o cotidiano, mesmo que haja políticas de "implementação" e/ou mecanismos de controle. Os professores que atuam no contexto da prática, mesmo que quisessem, não poderiam seguir os textos curriculares em sua proposição original ou "pura". Esses profissionais têm histórias de vida, interesses e disposições próprios (LAHIRE, 2006). Tais disposições geram formas distintas de interpretar os textos. Aquilo que será enfatizado, selecionado, rejeitado, ignorado e/ou mal-entendido dependerá do modo com o qual os leitores dão significado ao texto, seja ele um texto do tipo "escrevível" (writerly) - que potencializa as possibilidades de reescrita - ou do tipo prescritivo (readerly) - que tende a restringir o envolvimento do leitor (BARTHES, 2019).

Há mais uma característica importante no contexto da prática: as diferentes interpretações dos textos curriculares disputam espaço por legitimidade. Apesar de serem diversas, determinadas formas de interpretação são predominantes. Também há conflito na esfera das práticas curriculares. E é desse modo que as interpretações e traduções dos professores que atuam no contexto da prática dão o sentido circular à teoria de Ball e Bowe (1992) - a abordagem do ciclo de políticas. As interpretações que se tornam predominantes nas práticas curriculares vividas no cotidiano vão gerar impacto nas outras esferas da dinâmica curricular. 
Essa teoria que, resumidamente, apresentamos nesta introdução, permite um olhar para a dinâmica curricular que a visualize de modo amplo, panorâmico e com capacidade de capturar complexidades. O currículo da EF tem sido objeto de um número crescente de estudos no Brasil, especialmente na última década (ROCHA et al., 2015). Esses estudos têm contribuído, às suas medidas, para possibilitar que a EF se apreenda mais e melhor e, a partir disso, consiga reorganizar a sua dinâmica curricular. Nessa mesma direção, este estudo pretende contribuir para a construção dessa EF que queremos ter/ser. Esta nossa contribuição guarda a peculiaridade desse olhar que deseja aliar amplitude com complexidade. Especificamente, procuramos responder à seguinte questão: como a dinâmica curricular da EF (em toda a sua amplitude) pode ser compreendida a partir do currículo vivido na EF em uma escola de referência? Como as particularidades de um projeto de educação extraordinário (escola de referência) incidem sobre a dinâmica curricular?

O artigo, portanto, leva em consideração que o currículo tem sua dinamicidade e pluralidade, e tem o objetivo de descrever e compreender como as políticas curriculares na Secretaria de Educação de Pernambuco são acessadas e traduzidas em ações pedagógicas, durante as práticas curriculares vivenciadas no cotidiano das aulas de EF em uma escola de referência de ensino médio.

\section{Metodologia}

A análise das práticas curriculares foi realizada através de uma pesquisa etnográfica vivenciada em uma escola de referência situada em um município do sertão pernambucano. Um dos autores da pesquisa ficou imerso em campo para as coletas durante três meses, tempo no qual permaneceu na condição de observador participante das aulas de um professor específico. Nesse período, foram observadas 14 aulas de duas turmas do ensino médio, uma 
de $2^{a}$ série e uma de $3^{a}$. Nas turmas observadas, as aulas aconteciam nas segundas-feiras à tarde e nas sextas-feiras pela manhã. O calendário das aulas de EF, feito pelo professor, foi organizado com aulas práticas e teóricas. Além das observações das aulas, atividades relacionadas à coordenação e gestão da escola também foram observadas. Desse modo, a observação transcendeu os tempos e espaços nos quais eram desenvolvidas as aulas de EF e procurou contemplar os momentos de organização pedagógica que, de alguma forma, influenciam na rotina das aulas.

Os instrumentos de coleta de dados utilizados foram uma ficha de observação etnográfica, com pontos marcados para sublinhar a atenção do observador, um diário de campo no qual foram anotadas as informações cotidianas referentes à etnografia e entrevistas abertas com os dois professores de EF que estiveram lotados na escola estudada. ${ }^{2}$ Nas fichas de observações os quesitos abordados foram em relação à quantidade de alunos no início, meio e fim da aula; aos temas e conteúdo das aulas; à participação dos alunos levando em consideração as questões de gênero; à estrutura da aula; ao relacionamento dos alunos com o professor; às possíveis atitudes discriminatórias (relacionadas a gênero, raça/ etnia, sexualidade e outros); às formas de avaliação utilizadas nas aulas; e às ocorrências relevantes observadas.

Os resultados estão apresentados em três seções: o cenário da pesquisa, diário de campo e fichas de observação etnográficas. Na primeira seção há uma contextualização do ambiente estudado, a fim de favorecer a visão panorâmica postulada pelo referencial teórico que utilizamos. Nas duas últimas seções, apresentamos, mais enfaticamente, os dados decorrentes da imersão no campo. Esses dados foram tratados através de análise de conteúdo (BARDIN, 2011). Foi realizada uma organização dos dados através da separação por temáticas, tanto as pré-estabelecidas nas fichas de observação etnográficas quanto as que surgiram, de forma menos circunscrita, nos diários de campo e nas entrevistas. As temáticas pré-estabelecidas estão descritas no parágrafo ante-

2 Foram realizadas entrevistas com o professor que estava trabalhando com a disciplina EF durante a realização da pesquisa e também com o outro professor que o antecedeu nessa função e não está mais atuando na rede. 
rior a este, já as que foram percebidas durante as observações e entrevistas são as seguintes: valorização da disciplina EF, participação dos estudantes, pontualidade, didática peculiar, questões de gênero e avaliação. Essas últimas, as temáticas que foram categorizadas a posteriori, a partir dos dados coletados, não foram definidas em função da quantificação de determinados eventos. A definição das categorias temáticas teve a dinâmica curricular como norte. Selecionamos, nessa direção, os grupos de informações que estavam presentes nos dados coletados que pudessem gerar associações com esse objeto. Posteriormente, os dados foram transformados em descrições e análises. Optamos, em função da restrição imposta pelo tamanho do artigo, por apresentar o texto com a descrição dos resultados sem inserir trechos de nossas fontes primárias (os escritos do diário de campo, as transcrições das entrevistas e as anotações das fichas de observação).

A execução da pesquisa foi aprovada por um Comitê de Ética em Pesquisa (CEP) ligado à Comissão Nacional de Ética em Pesquisa (CONEP). O número de registro do projeto (CAAE) no referido comitê é 14437019.3.0000.5196.

\section{O cenário da pesquisa}

A escola na qual realizamos a coleta dos dados desta pesquisa é uma das Escolas de Referência em Ensino Médio (EREM) da Secretaria de Educação do Estado de Pernambuco. As EREM passaram a constituir uma política pública educacional com a publicação da Lei Estadual Complementar n. 125 (PERNAMBUCO, 2008), instalando-se, inicialmente, em 20 escolas experimentais que já se encontravam em funcionamento. A partir da efetivação dessa política, as EREM passaram a funcionar com características especiais no que se refere à duração da jornada escolar; à carga horária curricular anual do ensino médio integral e semi-integral; às condições de infraestrutura das escolas; à composição da equipe gestora, à carga horária de trabalho e às principais atribuições dessa 
equipe; ao salário e ao processo de ingresso do professor no quadro docente da escola de ensino médio integral (DUTRA, 2013).

As EREM foram idealizadas com o propósito de sanar um dos grandes problemas relacionados ao ensino médio, que é a evasão escolar, e também foram utilizadas como um modelo com vistas à melhoria dos índices que aferem a qualidade do ensino. E, de fato, nesse nível de escolarização, o estado de Pernambuco obteve uma melhoria significativa no que tange à avaliação apresentada no IDEB - no ano de 2007 seu índice estava aferido em 2,7, em 2017 foi para 4,0 e em 2019 chegou a 4,4 (BRASIL, 2020). Percebam que, para chegar a esses números, as políticas educacionais desse estado têm se pautado de sobremaneira nos exames que aferem o desempenho da educação. De acordo com Ball (2005), essa hipervalorização, da avaliação institucional como diretriz para políticas públicas educacionais é uma tendência global. A busca por um posicionamento mais elevado nos diversos rankings que comparam os desempenhos das redes de educação, sejam estatais ou privadas, tem se constituído como um novo regime de verdade. Os números desses rankings são, nesse sentido, um potente fator de influência sob uma ideologia da performatividade. Segundo Ball (2005, p. 543), “a performatividade é uma tecnologia, uma cultura e um método de regulamentação que emprega julgamentos, comparações e demonstrações como meio de controle, atrito e mudança". E, para estabelecer o seu modus operandi, ela desenvolve e veicula informações e indicadores para estimular, julgar e comparar profissionais e instituições.

No que se refere às prescrições curriculares, em 2008 os professores de EF das EREM foram chamados para uma ação com vistas ao desenvolvimento de um parâmetro curricular específico e exclusivo, considerando as supracitadas especificidades dessas escolas de referência. Esse encontro, que aconteceu no Recife, contou com a presença de professores de todo o estado. De lá surgiu um material próprio para atender a todas as EREM. Esse material foi utilizado por alguns anos, mas depois ficou em desuso. 
Atualmente as EREM têm utilizado o mesmo documento curricular das demais escolas estaduais de Pernambuco.

Nas entrevistas que realizamos com os professores foi discutido o perfil exclusivo dessas escolas, que eram percebidas, e ainda são, de acordo com a fala dos dois professores entrevistados, como uma "ilha de referência". Essa característica deve-se aos privilégios que as EREM possuem, se compararmos com a realidade das escolas ordinárias da rede estadual de Pernambuco, que, assim como na maioria dos estados brasileiros, carecem de recursos para manterem seus funcionamentos básicos. De acordo com o relato dos professores, logo no início do programa, quando no mesmo espaço físico estavam agrupados, em salas diferentes, alunos da rede estadual e alunos matriculados nas EREM, existiam fortes diferenças estruturais. Alunos matriculados nas EREM recebiam a merenda escolar, ao mesmo tempo em que os alunos que estavam na sala da frente, que eram da rede estadual ordinária, não recebiam. Isso mostra a forma pela qual uma política de Estado ofereceu recursos e atendimentos desiguais para crianças que tinham necessidades semelhantes. O programa tinha uma subsecretaria que cuidava exclusivamente das escolas integrais de referência, suprindo suas demandas. Essa lógica de distinção, que ainda é evidente, coloca as escolas de referência em um patamar diferenciado, no qual os professores também têm uma representação distinta.

Também foi relatado que o programa teve parcerias privadas que, unidas com o Estado, desenvolveram o projeto das escolas de referência. Entre as empresas privadas estavam a Philco, a Philips e a Odebrecht. Nessa via, não é de se surpreender que o balaio dessas parcerias público-privadas carregue interesses que ultrapassam os aspectos educacionais. Naturalmente, o setor privado tem seus interesses e ideologias particulares, e essas parcerias constituem uma forma de mover as peças na complexa teia das políticas curriculares. Como o movimento neoliberal, que pretende a privatização dos serviços públicos, não consegue atingir direta e completamente a educação básica pública e gratuita, as par- 
cerias público-privadas abrem caminho para mais ingerências e representatividades dessa ideologia (ROBERTSON, 2012).

Um de nossos entrevistados também evidenciou que, mesmo com todo esse aparato de distinção das EREM, alguns fatores não são viáveis para uma boa "estadia" do professor. Por ser uma proposta de referência na educação de Pernambuco, acreditava-se que o quadro salarial fosse adequado, a fim de estabelecer, também entre a classe de professores, um ambiente com condições adequadas. No lugar disso, foi possível identificar que a gratificação é muito vulnerável, pois se trata de um ambiente que só aceita o trabalho do professor com dedicação exclusiva. A princípio, esse seria um fator positivo, pois possibilitaria um acréscimo no vínculo de identidade do professor com a escola. Mas, como pudemos identificar no relato dos professores entrevistados, o salário oferecido para os professores das EREM não supre as necessidades materiais desses trabalhadores. Nas palavras de um desses entrevistados, "é difícil achar professores que queiram ficar só nas escolas de referência, pois não compensa financeiramente" (Professor 2, entrevista, 17 mar. 2016).

O professor que tivemos a oportunidade de acompanhar durante a fase de observação é veterano nas EREM. Antes de atuar na escola na qual ocorreu esta pesquisa, ele trabalhava em outra escola de referência localizada no mesmo município. Ele foi transferido para o nosso campo da pesquisa em fevereiro de 2016 dois meses antes de iniciarmos as coletas. Esse professor tinha, naquele momento, 11 anos de experiência profissional e estava cursando o mestrado em EF, conciliando o exercício docente com a sua formação acadêmica. Ele também esteve presente no processo de construção das prescrições curriculares para a EF do programa EREM, tendo participado das reuniões que aconteceram em 2008 - consideradas, por ele, extremamente relevantes para a construção do currículo.

A escola na qual estivemos imersos fica localizada em um município do Sertão de Pernambuco, em uma das principais vias urbanas da cidade, em um bairro de classe média baixa. Quanto às 
instalações físicas, a escola possui 18 salas de aula, além de outras salas que servem de laboratórios, ambientes para reuniões, biblioteca e auditório. Ela também possui uma quadra poliesportiva coberta em bom estado de conservação, utilizada para as aulas de EF e para outras atividades educacionais. A escola tinha, no ano de 2016, 765 estudantes matriculados e contava com 34 professores de várias disciplinas.

Um fato relevante sobre as características dessa escola relaciona-se com os bons resultados no Índice de Desenvolvimento da Educação Básica (IDEB). Em 2010 ela foi a segunda melhor do estado de Pernambuco, destacando-se, ainda mais enfaticamente, no âmbito educacional de sua cidade. Esses números alcançados pela escola, e a exaltação deles na sua representação como uma instituição de prestígio da região, revelam uma teleologia direcionada para a performatividade. A obtenção de resultados expressivos nos índices que comparam a escolarização fornece credenciais de distinção, sejam simbólicas (o prestígio, o empoderamento) ou materiais (como exemplo, as bonificações salariais para os professores das escolas com bons números). Na escola em que foi realizada a pesquisa, essas credenciais constituem um fator de relevância para a cultura da escola (DEMENECH; DICKEL, 2016), que certamente reverberam nas definições e disposições de seu cotidiano.

\section{Diário de campo}

A entrada no campo de pesquisa foi marcada por uma recepção agradável por parte dos alunos e nossa presença logo se tornou mais integrada. Descobrimos que essa rápida integração ocorreu em função das turmas estarem familiarizadas com estagiários nas aulas de EF. Além dessa sensação de sermos bem recebidos, percebemos de imediato que o local era organizado e que havia espaço físico suficientemente adequado para a realização das aulas. As primeiras observações também sugeriram que a EF 
era uma disciplina valorizada pelos estudantes. Não aparentava, portanto, ser secundarizada. Por se tratar de uma escola de referência de ensino médio, com a performatividade em evidência, e como os conteúdos da EF não costumam fazer parte das avaliações de larga escala, incluindo-se o ENEM, essa secundarização era, em alguma medida, hipotetizada.

A participação dos estudantes das duas turmas observadas durante todas as aulas chamou a nossa atenção já nos primeiros dias de observação, e contribuiu ainda mais para afastar a hipótese da secundarização. Acreditamos que parte dessa permanência dos alunos nas aulas pode ser explicada pela forma com que o professor conduz, didaticamente, o processo de ensino e de aprendizagem. Em suas palavras, "não existe a opção de não fazer a aula" (Professor 1, entrevista, 30 mar. 2016). Foram raras as exceções. Presenciamos casos de alunos que apresentaram atestados médicos, restringindo a prática de atividade física, ou alunos temporariamente impossibilitados para as aulas. No entanto, mesmo esses alunos eram, de alguma forma, envolvidos nas aulas.

A pontualidade no horário das aulas foi outro aspecto registrado no diário de campo. Durante o período de observação, a turma da $2^{a}$ série foi prejudicada no que diz respeito ao tempo de duração das aulas. Como o início dessas aulas estava programado para o primeiro tempo depois do intervalo para o lanche, o cumprimento do horário estabelecido foi dificultado. Na maioria das vezes o professor teve um desgaste adicional para conseguir iniciar as atividades previstas. Em uma ocasião específica, a turma ficou dispersa a tal ponto que impossibilitou a continuidade do conteúdo planejado. Além dos atrasos decorrentes do comportamento agitado da turma no horário pós-intervalo, o transcorrer das atividades planejadas era dificultado pela poluição sonora proveniente de uma avenida bastante movimentada que passa ao lado da quadra. O barulho da rua, agregado ao dos alunos, dificultava as explicações das atividades. Para contornar essa dificuldade o professor iniciava as aulas em sala, de tal modo que os alunos já chegavam na quadra sabendo o que deveriam fazer. 
Outro fato que pudemos evidenciar durante as nossas observações foi que o professor tinha uma estratégia didática peculiar: uma espécie de comportamento grosseiro e inflexível, mas, ao mesmo tempo, denotando afeto e empatia com os alunos. Por sua vez, os alunos entendiam essa linguagem bem singular e a respeitavam, demonstrando reciprocidade ao afeto subliminarmente emitido pelo professor. As primeiras observações nos deixaram perplexos, mas depois começamos a perceber que os alunos se identificavam com aquele tipo de tratamento aparentemente rude. O professor aparentava ser duro e intransigente, mas sabia a hora de elogiar quando a turma desenvolvia os trabalhos de forma bem-feita. Moura e Lovisolo (2017) discutem "a violência ritual" nas aulas de EF a partir do caso de um professor que tinha um comportamento semelhante, porém com maiores proporções no que se refere às dramatizações de violência.

No que se refere às questões de gênero observadas, notamos que o professor não separou as turmas por sexo. Ele relatou que nunca separava a turma considerando como critério o sexo dos alunos, e pudemos perceber que, de fato, os alunos e as alunas eram acostumados a participar das atividades propostas de forma interativa. Ocasionalmente, observamos uma divisão espontânea dos estudantes, mas na grande maioria das aulas não houve essa separação.

Em uma de nossas observações, a turma da $3^{a}$ série teve a aula de EF suspensa e os alunos foram encaminhados para o auditório para participarem de um processo de avaliação. A gestão da escola tem uma estratégia para que os alunos avaliem seu próprio desempenho ao final de cada unidade. Essa avaliação ganha mais importância para as turmas da $3^{a}$ série na medida em que se aproximam os exames para acesso ao ensino superior. Na reunião que pudemos presenciar, foram demonstrados e analisados, de forma estatística, o ranking das turmas, a média detalhada das notas em cada disciplina e houve espaço para um debate sobre o que pode ser feito para melhorar esses números. Na ocasião, os alunos puderam falar das dificuldades com determinados professores ou 
disciplinas. A EF não fica de fora dessa avaliação, sendo analisada como as outras disciplinas. Mas como o foco da coordenação está nos resultados insatisfatórios dessa análise, e no dia em que presenciamos essa dinâmica os alunos da $3^{a}$ série apresentaram bons resultados estatísticos em EF, suas dinâmicas nessa disciplina não foram problematizadas.

\section{Fichas de observação etnográfica}

A partir dos dados coletados com as fichas de observação etnográficas, foi possível constatar, nas duas turmas observadas, que os alunos participaram ativamente das aulas. Preocupados com a possibilidade de observar em quais momentos dessas aulas os alunos estariam mais ativos e em quais ocasiões eles tenderiam a deixar de participar das atividades propostas pelo professor, nós inserimos, nas fichas de observação, campos para aferir o percentual dos alunos ativos em diferentes momentos das aulas. A forma de utilização desses campos não teve grande utilidade, uma vez que os alunos participavam de todas as atividades. Esses dados retratam um panorama incomum frente aos dados encontrados na literatura que aborda essa temática na EF (MILLEN NETO et al., 2010). A partir de uma análise contextual, ficou sugerido que essa participação plena foi induzida por dois motivos em especial: as características próprias da dinâmica da escola e as estratégias didáticas do professor.

A escola na qual foi realizada a pesquisa procura aplicar estratégias para potencializar a eficácia de suas dinâmicas, com vistas à obtenção de resultados que contribuam para recredenciar a sua distinção - em que pesem as críticas a essa lógica performática de educação. Dentre essas estratégias há uma para potencializar a permanência dos alunos nas aulas. Existe um cartão que serve como autorização do professor para os alunos se ausentarem temporariamente das aulas. Sem esse cartão, os alunos não podem transitar pela escola durante o período de aula. Assim, não há 
a possibilidade de algum aluno não ir à aula de EF ou se ausentar dela sem a autorização do professor. Além disso, a EF nessa escola pode levar o aluno à reprovação, prática pouco usual em outras escolas da região estudada. Percebemos, com esse quadro, que esses dispositivos de controle dos corpos dos alunos nos tempos e espaços da EF mostraram-se efetivos. Com isso, se por um lado incrementou-se a participação plena nas aulas de EF, por outro, aplicou-se uma disciplina corporal com os mecanismos clássicos de controle - vigilância hierárquica, sansões normatizadoras e exames (FOUCAULT, 2002).

O perfil do professor que acompanhamos também contribuiu para essa participação plena nas aulas de EF, assim como para os processos de vigilância e controle dos corpos dos alunos. Com sua postura rígida, ainda que dramatizada, não havia a possibilidade de os alunos não participarem das atividades. Aqueles que porventura não o quisessem, eram obrigados. Mas é preciso destacar que a maioria dos alunos demonstrava interesse pelas aulas e participavam demonstrando satisfação.

Com relação aos conteúdos curriculares, o professor que acompanhamos durante a pesquisa foi enfático ao demarcar sua opção por não seguir as prescrições curriculares para a EF da Secretaria de Educação de Pernambuco - os Parâmetros Curriculares de Educação Física: ensino fundamental e médio (PERNAMBUCO, 2013). Por considerar que as especificidades do cotidiano de sua escola e da região na qual ela se localiza devem ser preponderantes frente a um projeto de unificação curricular, ele constrói seu próprio plano de trabalho de forma independente. Nossos registros de campo mostram que o currículo vivenciado no cotidiano das aulas desse professor é marcado pela diversidade de conteúdo, incluindo-se conteúdos que fazem parte da cultura corporal própria da região do Sertão de Pernambuco - como o Samba de Véio. De um modo geral, nos três meses de observação, vivenciamos aulas com os conteúdos de variados tipos de lutas, de danças, de ginásticas e ainda dos exergames. ${ }^{3}$

\footnotetext{
3 Exergames são jogos eletrônicos cuja tecnologia permite a captura e a interação dos movimentos corporais dos jogadores. Dessa forma, esses jogos permitem e estimulam uma dinâmica de exercícios corporais muito mais ampla do que ocorre nos videogames tradicionais.
} 
Notem que esse professor foi o mesmo que participou das reuniões para a elaboração das prescrições curriculares para a EF nas EREM, e foi o mesmo que considerou essa experiência como relevante. Mas lembrem-se também que as prescrições curriculares específicas para as EREM foram abandonadas e, em seu lugar, foram postas as prescrições gerais para toda a rede de ensino. Apesar do estado de Pernambuco ter uma tradição significativa na construção de prescrições curriculares para a EF, que tradicionalmente sistematizam a participação dos professores que atuam nas escolas (TENÓRIO et al., 2015), esse professor em específico não vê o seu contexto representado pelo documento oficial e abre mão de dialogar com ele. Há, portanto, um enfraquecimento na capilarização do fluxo das políticas curriculares, uma vez que as práticas curriculares vivenciadas no cotidiano não fazem uma tradução literal das políticas oficiais. A relação multidirecional entre as prescrições e o cotidiano, como Marani, Sanches Neto e Freire (2017) observaram em professores da rede municipal de Barueri/ $\mathrm{SP}$, parece estar comprometida no contexto observado pelo presente estudo.

Por último, destacamos as formas de avaliação que esse professor utilizou em suas aulas. Nos momentos em que estivemos com ele, observamos as seguintes estratégias para a avaliação do processo de ensino e de aprendizagem: portfólios produzidos pelos alunos, apresentações de trabalhos e uma rotina de observação de comportamento. Pudemos notar que os alunos, de um modo geral, davam importância a essas atividades, eram cuidadosos com relação à sua elaboração e costumavam cumprir os prazos acordados. Os portfólios, em especial, demonstraram ser uma forma de avaliação bem interessante. Constituindo-se em um registro geral das percepções dos alunos sobre as atividades vivenciadas, esses portfólios foram elaborados baseando-se nos apontamentos que os alunos eram estimulados a produzir a cada dia de aula. No final do semestre, os apontamentos eram transformados em um memorial, sob a forma de um portfólio, que guardava a percepção dos alunos sobre os conteúdos experienciados nas aulas de EF. 


\section{Considerações}

Os dados permitem afirmar que houve plena participação dos alunos nas aulas observadas. A partir dessa constatação, procuramos demonstrar o que fez a diferença na dinâmica das aulas para que os alunos se mantivessem presentes e ativos. A estrutura da escola, com seus controles e rigores, mostrou-se importante nesse aspecto. A postura didática do professor, com suas peculiaridades, também foi preponderante. Além disso, nossos registros capturaram outros aspectos que se agregam a esses primeiros. A prática do planejamento do professor que, no lugar de seguir um modelo prescrito ou restrito (a umas poucas modalidades esportivas), contextualizou e diversificou seus conteúdos, mostrou-se importante para a motivação e interesse dos alunos - o estudo de Lopes et al. (2016) reforça esta assertiva. Também ficou sugerido que há relação entre o modelo de avaliação utilizado pelo professor e a forma com a qual os alunos creditam importância às aulas de EF. Determinados modelos de avaliação poderiam induzir os alunos a ter mais autonomia para refletir sobre suas práticas corporais. Nos nossos achados foi possível perceber que o professor usou de vários meios para avaliar, facilitando o processo didático e fazendo com que os alunos pudessem expressar de diferentes formas o que tinham aprendido.

Outro aspecto relevante que permeou a tessitura das práticas curriculares observadas neste estudo diz respeito à ideologia da performatividade. Ainda que o professor de EF, cujas aulas foram observadas, tenha abdicado das prescrições curriculares oficiais, descapilarizando, em alguma medida, o fluxo das políticas curriculares, a influência de determinados dispositivos curriculares manteve-se operante. Por se tratar de uma escola de referência, cujo prestígio é conferido a partir de seus escores obtidos em avaliações educacionais de larga escala, a cultura dessa escola valoriza e contribui para constituir disposições para a eficácia. Nesse ambiente cultural, a organização curricular tende a um pragmatismo 
que busca constantemente eliminar a desordem dos tempos e espaços das práticas curriculares, como foi verificado no cotidiano das aulas de EF.

Corroborando a teoria do ciclo de políticas de Stephen Ball (1994), que destaca a complexidade das conexões que se estabelecem na dinâmica curricular, pudemos verificar que esse pragmatismo típico das políticas da performatividade concorre com outros dispositivos. Em nosso estudo, a performatividade pretendida pela escola de referência teve que se dispor ao modo pelo qual seu professor de EF optou por (não) lidar com as prescrições curriculares da Secretaria de Educação. Uma organização curricular que vislumbre pragmatismo e eficácia não costuma se afastar, e muito menos abdicar, de prescrições curriculares. Seguir as prescrições à risca geralmente favorece a obtenção de bons números (resultados) nos processos avaliativos de larga escala. E esses números, lamentavelmente, são a razão de ser de muitas políticas educacionais. Nesse sentido, é curioso o fato do professor de EF, cujas aulas observamos, ter toda essa autonomia para decidir a condução da organização curricular de suas políticas em uso (policy-in-use) vividas no cotidiano, à revelia das políticas efetivas (actual policy) presentes nos textos curriculares da Secretaria de Educação. Futuras pesquisas podem ajudar a compreender melhor esse processo.

\section{Referências}

BALL, S. J. Education reform: a critical and post-structural approach. Buckingham, UK: Open University Press, 1994.

BALL, S. J. Diretrizes políticas globais e relações políticas locais em educação. Currículo sem Fronteiras, Porto Alegre, v. 1, n. 2, p. 99-116, jul./dez. 2001.

BALL, S. J. Profissionalismo, gerencialismo e performatividade. Cadernos de Pesquisa, São Paulo, v. 35, n. 126, p. 539-564, set./ dez. 2005. 
BALL, S. J.; BOWE, R. Subject departments and the "implementation" of Nacional Curriculum policy: an overview of the issues. Journal of Curriculum Studies, London, v. 24, n. 2, p. 97-115, 1992.

BALL, S. J.; MAGUIRE, M.; BRAUN, A. How schools do policy: policy enactments in secondary schools. London: Routledge, 2012. BARDIN, L. Análise de conteúdo. São Paulo: Edições 70, 2011. BARTHES, R. O prazer do texto. 6. ed. São Paulo: Perspectiva, 2019.

BRASIL. MEC. Instituto Nacional de Estudos e Pesquisas Educacionais (Inep). IDEB - Resultados e Metas, 2020. [Online]. Brasília: Inep, 2020. Disponível em: http://ideb.inep.gov.br/resultado/. Acesso em: 1 fev. 2021.

DEMENECH, F.; DICKEL, A. Cultura escolar e cultura da escola: produção e reprodução a partir dos fatores intraescolares. Revista Professare, Caçador, v. 5, n. 2, p.21-42, 2016.

DUTRA, P. F. V. Educação integral no estado de Pernambuco: uma realidade no ensino médio. 98 f. Dissertação (Mestrado profissional em Gestão e Avaliação da Educação Pública). Faculdade de Educação, Universidade Federal de Juiz de Fora, Juiz de Fora, 2013.

FOUCAULT, M. Vigiar e punir: história da violência nas prisões. 26. ed. Petrópolis, RJ: Editora Vozes, 2002.

LAHIRE, B. A cultura dos indivíduos. Porto Alegre: Artmed, 2006. LOPES, M. R. S. et al. A prática do planejamento educacional em professores de Educação Física: construindo uma cultura do planejamento. Journal of Physical Education. Maringá, v. 27, n. 1, e2748, 2016.

MAINARDES, J. Abordagem do ciclo de políticas: uma contribuição para a análise de políticas educacionais. Educação \& Sociedade, Campinas, v. 27, n. 94, p. 47-69, jan./abr. 2006. 
MARANI, L.; SANCHES NETO, L.; FREIRE, E. S. O currículo da Educação Física na rede municipal de Barueri: as percepções dos professores. Movimento, Porto Alegre, v. 23, n. 1, p. 249-264, jan./mar. 2017.

MILLEN NETO, A. R. et al. Evasão escolar e desinteresse dos alunos nas aulas de educação física. Pensar a Prática, Goiânia, v. 13, n. 2, p. 115, mai./ago. 2010.

MOREIRA, A. F. B.; MACEDO, E. Faz sentido ainda o conceito de transferência educacional? In: MOREIRA, A. F. B. (org.). Currículo: políticas e práticas. 9. ed. Campinas, SP: Papirus, 2006.

MOURA, D. L.; LOVISOLO, H. A violência ritual nas aulas de educação física. Journal of Physical Education. Maringá, v. 28, n. 1, e2822, 2017.

PERNAMBUCO, Secretaria de Educação do Estado. Estrutura das Escolas de Referência em Ensino Médio (EREM), 2008.

Disponível em: http://www.educacao.pe.gov.br/portal/?pag=1\&men=70. Acesso em: 1 fev. 2021.

\section{PERNAMBUCO Parâmetros Curriculares para a Educação}

Básica do Estado de Pernambuco. Parâmetros Curriculares para a Educação Física Ensinos Fundamental e Médio. Recife: SEE-PE e Undime (PE), 2013.

ROBERTSON, S. A estranha não morte da privatização neoliberal na Estratégia 2020 para a educação do Banco Mundial. Revista Brasileira de Educação, Rio de Janeiro, v. 17, n. 50, p. 283-302, mai./ago. 2012.

ROCHA, M. A.; et al. As teorias curriculares nas produções acerca da educação física escolar: uma revisão sistemática. Currículo sem Fronteiras, Porto Alegre, v. 5, n. 1, p. 178-194, jan./abr. 2015.

TENÓRIO, K. M. R.; et al. Propostas curriculares para a Educação Física em Pernambuco: entendimentos acerca do esporte.

Revista Brasileira de Ciências do Esporte, Porto Alegre, v. 37, n. 3, p. 280-288, jul./set. 2015. 
O ciclo de políticas e o currículo vivido na educação física em uma escola de referência Alvaro Rego Millen Neto • Cleuber de Souza Gonçalves • João Paulo Silva de Oliveira

\section{Publisher}

Universidade Federal de Goiás. Faculdade de Educação Física e Dança. Publicação no Portal de Periódicos UFG. As ideias expressadas neste artigo são de responsabilidade de seus autores, não representando, necessariamente, a opinião dos editores ou da universidade. 